\title{
"Ser pedagogo" para alunos egressos de um curso de pedagogia: dialogando com a prática formativa
}

\author{
Celia Maria Haas ${ }^{1}$ \\ Elisângela Fregonezi Diniz Ribeiro ${ }^{2}$
}

\section{RESUMO}

$\mathrm{O}$ artigo apresenta resultados de pesquisa voltada a identificar o significado de "ser pedagogo" para alunos egressos de um Curso de Pedagogia - Licenciatura, cujo projeto pedagógico assume compromisso de uma formação interdisciplinar. $\mathrm{O}$ estudo, de natureza qualitativa, envolveu alunos formados na vigência do Projeto Pedagógico do Curso de Pedagogia - Licenciatura, construído a partir das diretrizes curriculares fruto da Resolução CNE/CP 1/2006, cuja investigação analisa o texto legal e o Projeto Pedagógico implantado. Os alunos, questionados, reconheceram a qualidade do curso, mas não identificam a interdisciplinaridade vivenciada, e, apesar de reconhecerem a formação para a docência, apontam a frágil formação para a gestão.

Palavras-chave: Alunos Egressos. Diretrizes Curriculares. Projeto Pedagógico. Curso de Pedagogia.

\begin{abstract}
This study presents the results of a survey carried out to identify the meaning of being a pedagogue as seen by students graduating in Pedagogy-licentiateship, the pedagogic project of which was committed to provide an interdisciplinary formation. The students taking the survey got their degree after the implementation of the Pedagogic Project for the Pedagogy Course-licentiateship, in force after curricular directives defined by Resolution 1, from May15th, 2006. The methodology, centred on qualitative research, leaned on authors discussing teacher formation, examination of legal texts, scrutiny of the implemented Pedagogic Project, and on an empirical phase, in which students graduating at a private college in 2010 where interviewed/queried.
\end{abstract}

Keywords: Graduating students. Curricular directives. Pedagogic Project. Pedagogy Course. Interdisciplinarity.

\footnotetext{
1 Pedagoga, Mestre e Doutora em Educação pela Pontifícia Universidade Católica de São Paulo e Professora titular no Programa de Mestrado em Educação da Universidade Cidade de São Paulo. E-mail: celiamhaas@uol.com.br

2 Pedagoga pela universidade municipal de São Caetano do sul - USCS e professora da rede municipal de ensino de são Caetano do Sul. Email: - lidiniz_ribeiro@hotmail.com
} 


\section{Introdução}

Este texto apresenta o resultado de uma investigação realizada junto aos alunos formandos de 2010, do Curso de Pedagogia - Licenciatura, de uma Universidade Municipal do Estado de São Paulo, cujo interesse central foi saber qual o significado de ser pedagogo para esse grupo de alunos. Permeando essa questão, tinha-se por base o Projeto Político-Pedagógico desse curso, construído a partir das diretrizes consubstanciadas na Resolução $\mathrm{n}^{\circ}$ 01, de 15 de maio de 2006, que propôs uma formação comprometida com a interdisciplinaridade "entendida como um esforço de superar a fragmentação na formação dos futuros professores, [apresentando-se] na concepção do currículo do curso de Pedagogia" (PROJETO PEDAGÓGICO, 2009, p. 34). Nesse sentido, foi também propósito da investigação verificar se os alunos reconheceram a proposta formativa interdisciplinar, que se acreditava implementada.

O projeto pedagógico do curso em estudo foi elaborado com base nos princípios que norteiam a formação de professores no Brasil, a partir do que foi instituído pela Lei Federal $n^{\circ}$ 9.394, de 20 de dezembro de 1996, Lei de Diretrizes e Bases da Educação Nacional (LDBEN), bem como pela Resolução $n^{\circ} 1$, de 15 de maio de 2006, que institui as Diretrizes Curriculares Nacionais para o Curso de Graduação em Pedagogia - Licenciatura. No projeto pedagógico em estudo, afirma-se que a formação dos futuros professores cabe:

[...] aos espaços responsáveis pela escolarização docente compete possibilitar uma sólida formação teórica e interdisciplinar, de modo a possibilitar ao graduando compreender as bases históricas, políticas, sociais e culturais de seu campo de formação e atuação, ou seja, fazer com que se aproprie do processo de trabalho pedagógico a partir de uma análise crítica da sociedade e da realidade educacional brasileira (PROJETO PEDAGÓGICO, 2009, p. 32).

A opção metodológica para o curso em questão, segundo seu Projeto Pedagógico, propõe assegurar a qualificação profissional do futuro pedagogo e compromete-se a proporcionar aos estudantes

[...] oportunidades de pesquisar, vivenciar, exercer e aperfeiçoar, em situações reais de trabalho, o embasamento teórico metodológico articulando os eixos fundamentais de sua formação, a docência, pesquisa e gestão, em um diálogo interdisciplinar entre teoria e prática (PROJETO PEDAGÓGICO, 2009, p. 33).

Com a homologação das diretrizes curriculares para o Curso de Pedagogia, em 2006, surgiu um impasse, a mudança proposta pelas definições das finalidades do curso, o que exigiu rever a estruturação para adequá-lo às funções que o pedagogo deverá desempenhar. Não obstante esse fato, mesmo após as mudanças efetuadas no Projeto Político-Pedagógico do Curso de Pedagogia, ainda permanece uma incerteza quanto à 
viabilidade da formação do pedagogo na sua totalidade, pois há, nas novas diretrizes, um privilégio na formação do professor em detrimento da formação do bacharel.

Lawn (2001, p. 120) lembra que, em havendo uma nova proposta por parte do Estado, resulta na necessidade de adequação da identidade do profissional da educação, conforme segue:

As tentativas do Estado para criar novos tipos de professores para as novas orientações da política educativa, originadas em diferentes períodos deste século, têm sido as principais formas pelas quais a identidade do professor tem sido construída e mantida. O problema em decidir acerca dos objetivos e sistemas educativos nunca esteve afastado da construção de novas identidades do professor.

Entende- se, portanto, que as novas diretrizes curriculares para o Curso de Pedagogia desenham uma identidade e propõem um super professor, que deverá formar o cidadão, sentir-se à vontade com as novas tecnologias, ser capaz de trabalhar em equipe, comprometer-se com a inclusão, ter uma ação positiva no que se refere ao meio ambiente, atuar interdisciplinarmente e assegurar a aprendizagem em sala de aula. Pode-se assim, admitir que as novas e diversificadas competências citadas nas diretrizes parece que "criam uma cultura de excelência e de aperfeiçoamento do ensino" (LAWN, 2001, p. 128).

Preocupados com a formação proposta e motivados a verificar qual o significado de ser pedagogo, buscou-se o entendimento dos alunos sobre esse tema, questionando-os sobre a estruturação do curso, a proposição interdisciplinar e a atuação profissional dos professores, uma vez que sua formação está intimamente relacionada com a qualidade da educação básica.

A pesquisa constituiu-se de uma investigação de natureza qualitativa e de caráter exploratório, com foco nas orientações de (BOGDAN; BIKLEN, 1991), no campo das Ciências Humanas. Na primeira etapa, realizou-se a análise documental, tomando-se por base a obra de Lüdke e André, intitulada Pesquisa em educação: abordagens qualitativas, publicada em 1986, que tem por foco o estudo do Projeto Pedagógico, da legislação que regulamenta a oferta de cursos de pedagogia e da literatura pertinente e exigida para melhor compreensão do tema e problema. O foco de discussão e análise são as respostas a um questionário estruturado respondido eletronicamente por 46 alunos concluintes, da primeira turma do Curso de Pedagogia da referida universidade. O questionário foi elaborado para levantar dados relacionados às três categorias previamente definidas, a saber: categoria 1 - o significado de ser pedagogo; categoria 2 - o projeto pedagógico e o currículo; e categoria 3 - a nova legislação.

Preservando-se as identidades dos alunos participantes, as respostas estão 
organizadas por ordem alfabética e, no decorrer da análise dos eixos propostos, eles serão identificados por números (de 1 a 46).

\section{O que dizem os alunos}

Co $m$ as questões propostas na categoria 1 - o significado de ser pedagogo para os alunos do novo Curso de Pedagogia - Licenciatura - procurou-se identificar a percepção do aluno sobre o que significa ser pedagogo, sobre o seu papel, suas incumbências e sua área de atuação, além de investigar se o aluno encontrou o que buscava e avalia se ele se sentiu motivado ao longo do curso.

Quando questionados sobre o pedagogo que se está formando, 30 dos 46 alunos ofereceram respostas parecidas, relacionando o papel do pedagogo à atividade docente. Outros 11 alunos percebem a profissão do pedagogo como algo mais. Foi possível, também, verificar em cinco alunos a descrição desse profissional como um agente redentor da sociedade, pois, como afirma um deles: "ser pedagogo é saber lidar com o diferente, sem preconceitos, sem distinção de cor, raça, sexo ou religião. É ter uma responsabilidade muito grande nas mãos, acreditando no futuro do próximo" (ALUNO 29).

$\mathrm{Na}$ investigação proposta, como resultado da questão elaborada para saber se o aluno encontrou o que buscava no curso e avaliar se ele se sentiu motivado durante esse período de aulas, 38 alunos disseram ter encontrado o que buscavam no curso. Entretanto, do total dos respondentes, 29 alunos sentiram-se desmotivados em algum momento do curso; outros 7 sentiram-se motivados durante todo o curso; e 10 alunos não responderam diretamente sobre motivação. Uma aluna afirma: "para ser sincera, a parte teórica achei de grande valia. Mas não me senti muito estimulada durante o curso, acredito que as aulas precisam ser mais dinâmicas, e muito mais voltadas para o dia a dia na sala de aula" (ALUNO 22), enquanto outro destaca: "encontrei mais do que eu buscava, pois tinha uma visão de Pedagogia apenas como a possibilidade de lecionar ou ser diretora de uma escola, mas ao longo do curso pude ter maior conhecimento sobre as novas possibilidades de trabalho além do âmbito escolar" (ALUNO 18).

No que diz respeito ao papel e as funções atribuídas ao pedagogo, os alunos conseguiram conceituar e classificar essas funções como áreas de atuação, principalmente as ligadas à educação. Para 10 alunos, as funções do pedagogo não mudaram no decorrer do curso; 14 alunos acreditaram que as funções mudaram; 21 alunos não responderam diretamente sobre essa mudança; e um aluno não respondeu essa questão. Os 14 alunos que acreditaram na mudança das funções creditam-na, principalmente, à transformação para se adequar à exigência social e também às mudanças necessárias para atuar em outras áreas além da educação, conforme afirma um dos alunos: "as funções mudaram sim, hoje o pedagogo não está limitado ao âmbito escolar e sim a outros âmbitos” (ALUNO 18). 
Em relação às questões propostas na categoria 2 - Projeto Pedagógico e Currículo -, os alunos foram levados a refletir sobre currículo, interdisciplinaridade, contribuição do curso para sua formação profissional e se houve equilíbrio entre todas as formações abrangidas pelo profissional de Pedagogia.

Quando questionados sobre a forma como o curso contribuiu para a sua formação profissional, 44 dos 46 alunos informaram considerar a formação universitária como algo crucial para o bom desempenho de suas atividades e classificaram o conhecimento adquirido, bem como o embasamento teórico, vitais para a sua prática, como se pode ver na fala de um aluno, ao dizer: "de uma maneira muito significativa, pois, apesar de eu já trabalhar na área educacional há quase dez anos, ao longo do curso fui percebendo o quanto é importante uma formação superior qualificada para todos os profissionais da educação" (ALUNO 14).

É possível inferir, tomando-se por base a fala dos alunos, que para eles a formação universitária foi um grande impulso profissional, ainda que existissem algumas dúvidas sobre a hipótese de atuar em todas as áreas de formação (docência e gestão) propostas pelo curso. Como destaca Castro (2007, p. 218)

Essa proposta de formação [as diretrizes curriculares] de um professor capaz de participar das atividades administrativas condiz com a nova configuração do mercado de trabalho do gestor, que vem praticando uma gestão colegiada, sendo as atividades de todos os profissionais da escola previstas nos Projetos Político-Pedagógicos, elaborados coletivamente.

Castro (2007, p. 219) ainda complementa destacando: "assim, no momento atual, a base da identidade do pedagogo é a docência, a partir da qual é feita a preparação para a gestão educacional”.

No tocante às expectativas quanto aos objetivos do curso e se elas foram alcançadas, 23 alunos alcançaram seus objetivos; 6 alunos acreditaram que o curso não correspondeu às suas expectativas; 16 afirmaram que o curso correspondeu em parte; e um aluno não respondeu à questão. É importante citar que, apesar das avaliações já destacadas acima, eles são praticamente unânimes em defender um curso que privilegie a prática em detrimento da teoria, embora reconheçam o valor teórico do curso, pois, como afirma o aluno, "em parte, sinto falta de aulas práticas e simulações sobre a prática" (ALUNO 1). Destacando, ainda, a ausência da prática no processo formativo, outro aluno diz: "as minhas expectativas não foram todas sanadas [sic], pois eu achava que o curso teria mais aulas práticas do que teóricas, mas me ajudaram a ter um olhar diferenciado 
para a minha projeção no trabalho atual” (ALUNO 28).

No que diz respeito ao currículo e se este explicitava a interdisciplinaridade, o grupo dividiu-se nas respostas, pois 26 alunos acreditaram que estava explícita e foi realizada; 7 alunos argumentaram que não estava explícita; e 11 alunos disseram que o currículo até explicitava a interdisciplinaridade, mas essa proposta não aconteceu na sua totalidade. Do total de alunos, 2 não responderam essa questão. É possível verificar mais detalhes na fala do aluno que afirma: "em parte, pois houve muita dificuldade dos professores interagirem como equipe, mas é devido ao curso ser muito recente para se consolidarem e se identificarem para o trabalho interdisciplinar conjunto e coeso" (ALUNO 9). Outro aluno disse: "explicita sim, porém ainda acho que essa interdisciplinaridade deveria ser trabalhada de forma mais completa no decorrer do curso" (ALUNO 46). Destaque-se a fala de um aluno que afirmou: "acho que no $1^{\circ}$ ano a interdisciplinaridade foi um fator facilitador para todos, foi muito bom, pois, todas as disciplinas 'falavam a mesma língua', entretanto, nos anos subsequentes creio que pela própria natureza das disciplinas houve certa dificuldade para manter essa interdisciplinaridade, algo que foi notado e comentado por todos" (ALUNO 14). Interessante apontar o reconhecimento de um aluno que a interdisciplinaridade pode ser identificada, "sim, pois de certo modo algumas matérias sempre podiam ser ligadas a outros conteúdos de outro professor. Fizemos até trabalhos envolvendo mais de uma matéria" (ALUNO 37).

A última questão tinha por intuito saber se houve um equilíbrio entre a formação do professor - de séries iniciais e ensino fundamental I - e a do gestor. Investiga, também, se o aluno se sente preparado para atuar nessas áreas. Dos alunos que compõem a amostra, 25 acreditaram nesse equilíbrio entre as formações; 16 acreditaram que não houve equilíbrio; e 2 alunos não responderam à questão. Segundo um depoimento, "a formação de professor teve maior espaço, porém acredito que o necessário, a formação para gestor foi, a meu ver, apenas uma base, e que para atuar na área ainda preciso de um curso de especialização" (ALUNO 24).

Pelos depoimentos, é possível depreender que:

a) Dos 46 alunos, 14 afirmaram que estão aptos para trabalhar em todas as funções;

b) Nove alunos se sentem preparados para atuar somente na Educação Infantil;

c) Onze alunos se declaram aptos para trabalhar tanto no Ensino Fundamental quanto na Educação Infantil;

d) Umaluno se considera preparado para trabalhar somente no Ensino Fundamental;

e) Um aluno alega estar preparado para trabalhar somente na Gestão Escolar; 
f) Seis alunos não responderam diretamente à essa questão; e

g) Dois alunos não se sentem preparados para trabalhar em nenhuma das três funções (lembrando que dois alunos não responderam à questão proposta).

Pode-se observar a opinião dos alunos quando admitem: "quanto à educação infantil e fundamental, sim, são áreas em que atuo, em que me identifico e gosto. Quanto à gestão, o estágio propiciou averiguar a prática, porém não me sinto pronta para atuar" (ALUNO 12), enquanto outro pontua:

Não. Aprendi mais a ser professor do que gestor. Tive mais orientações e tarefas práticas em relação a ser professor do que gestor. Estou preparada para atuar como professora da educação infantil, do primeiro ciclo do ensino fundamental, mas, gestora, ainda não. Acho que não é muito pelo curso. Aprendemos nas aulas de gestão que é necessário passar pelo cargo de professor, coordenador (se possível), alguns cursos complementares de gestão e, a partir disso, sim. Porque é necessário ter uma bagagem de conhecimentos e experiências para atuar como gestor de escola. (ALUNO 16).

Interessante observar que, apesar da promessa do projeto pedagógico que acredita na formação das três funções básicas do futuro pedagogo (docência na educação infantil docência no primeiro ciclo do ensino fundamental e gestão escolar), os alunos destacaram a formação para a docência em detrimento da formação do gestor como mencionado por um aluno, isto é, "a formação de professor teve maior espaço, porém, acredito que o necessário, a formação para gestor foi, a meu ver, apenas uma base, e que para atuar na área preciso de um curso de especialização" (ALUNO 24), e as dificuldades com os conteúdos específicos do ensino fundamental também são admitidos, como diz uma aluna:

(...) sinto-me bem preparada para atuar como professora de educação infantil, do fundamental e também como gestora ou coordenadora pedagógica, tenho bem claro quais são os conhecimentos necessários e acredito que não teria problemas atuando nestas áreas. Sinto-me ainda um pouco insegura para atuar no ensino fundamental, acredito que os currículos atuais e a forma como são distribuídos os conteúdos acabam dificultando um pouco o ensino e aprendizagem; eles não favorecem a interdisciplinaridade, são densos e requerem prazos curtos para serem desenvolvidos. (ALUNO 33).

Reconhecendo assim uma das condições da interdisciplinaridade que diz respeito 
ao domínio do conteúdo, inúmeras vezes discutido por Fazenda (1991, 1994, 2003) e destacado por Haas (2007, p. 189) quando pontua que "apontamos também a erudição como característica da interdisciplinaridade, pois é preciso saber muito, ter gosto pela leitura, pela pesquisa e pela busca de mais e melhores conhecimentos, o que conduz forçosamente a outra exigência interdisciplinar: a dúvida".

Com as questões propostas na categoria 3 - A nova Legislação, buscavase identificar o conhecimento e o entendimento do aluno sobre o Projeto Pedagógico proposto pelas Novas Diretrizes Curriculares para o curso de Pedagogia, de acordo com a Resolução $\mathrm{n}^{\mathrm{o}} 1$, de 15 de maio de 2006. Também se buscava levantar a opinião dos alunos para saber se o horário e a duração do curso foram suficientes; se a proposta do curso era formar um superprofessor e, por fim, buscar sugestões sobre o que deveria ser mudado no Projeto Pedagógico, no currículo e no horário do curso que eles concluíram.

Pode-se dizer que a questão relativa à Proposta Pedagógica das Novas Diretrizes Curriculares, fruto da Resolução de 2006, teve maior abstinência quanto à resposta dos alunos. Dos 46 componentes da pesquisa, 13 não a responderam, fato que parece indicar desconhecimento, de um modo geral, da legislação que trata da formação do pedagogo.

Dos alunos respondentes, 9 afirmaram não saber sobre o que tratava a Nova Proposta. Catorze alunos demonstraram não ter ideia clara sobre o assunto, como se identifica na fala de um aluno: "acredito que a resolução acrescentou pontos positivos à grade dos cursos de pedagogia, visando melhor formação docente" (Aluno 14). Do total participante, 10 alunos conseguiram expressar uma ideia da proposta das Novas Diretrizes Curriculares, conforme se verifica, a seguir:

O movimento de reorientação curricular desenvolvido pelo Conselho Nacional de Educação é um processo histórico no qual instituiu as novas Diretrizes Curriculares para o Curso de Pedagogia, transformando-o em uma licenciatura, cuja função principal é formar o professor para atuar na Educação Infantil, séries iniciais e na formação de professores em escolas normais" (ALUNO 37).

No questionamento para saber se o horário do curso - noturno - e a duração das aulas - com aulas presenciais de segunda a sexta -, 42 alunos admitiram que foram suficientes; 3 alunos acreditaram que não foram suficientes; e 1 aluno não respondeu claramente. É importante destacar que 3 alunos consideraram produtivas quatro aulas da mesma disciplina no mesmo dia, afirmando, por exemplo, que "sim, até pelo fato de serem as quatro aulas na noite com o mesmo professor, deu para aproveitar bastante, sem ter de iniciar e parar pela metade" (ALUNO 13); e 5 não aprovaram pelo fato de sobrecarregar 
o aluno, pois "até foi, mas acho que as aulas podiam ter sido mais produtivas se fossem distribuídas com pelo menos duas matérias por dia, para que não ficasse cansativo o curso. Mas quanto à carga horária, foi o suficiente" (ALUNO 37).

Pode-se destacar que a organização do horário de aula precisa considerar as características dos professores, uma vez que há certo consenso de que há 2 horas aula para cada disciplina e a mudança nessa prática exige uma nova postura dos docentes, como diz um aluno "sim, no início quando fomos informados que teríamos um professor só por dia, tratando da mesma matéria, achei que seria cansativo, mas com o decorrer do curso, percebi que foi produtivo por não precisar interromper a aula em um curto espaço de tempo, tendo assim mais conteúdos e atividades por dia" (ALUNO 40). Pensar em novas alternativas para a atuação docente tem sido refletido intensamente pelos estudiosos da interdisciplinaridade (FAZENDA, 1991; 1994; LENOIR, 2005) e como afirma Haas (1996, p. 57)

(...) a interdisciplinaridade impõe um novo relacionamento entre professor e aluno. $\mathrm{O}$ professor não é mais aquele que transmite conhecimento ao aluno, mas é aquele que auxilia o aluno a descobrir, a construir e a se apropriar dos conhecimentos necessários para uma ação consciente no mundo.

Fazenda (2011, p. 10) reconhece que "interdisciplinaridade é uma nova atitude frente à questão do conhecimento, de abertura à compreensão de aspectos ocultos do ato de aprender e dos aparentemente expressos, colocando-os em questão".

No que diz respeito à proposta de se formar um superprofessor, nesse curso, os alunos foram unânimes em afirmar que isso não é possível, com alegações da seguinte ordem: "acredito que o curso de Pedagogia forma Mestres, que, diferentemente de superheróis, são mediadores que se oculta [sic] para elevação do educando" (ALUNO 2); ou, ainda: "não de um 'superprofessor', mas um educador capaz de prever e sentir a necessidade do grupo de alunos, e de cada aluno em particular, fazendo do seu lecionar uma aprendizagem significativa para todos, inclusive para ele mesmo" (ALUNO 26).

Na última questão desse eixo, buscava-se a opinião dos alunos acerca do processo formativo pelo qual passaram. Essa questão transformou-se em um canal aberto com o aluno, permitindo-lhe expor seu ponto de vista e apontar aquilo que poderia ser melhorado. Dos 46 alunos, apenas um não respondeu a essa questão. Nesse questionamento, dos 45 respondentes, pode-se aferir que a maior discussão relaciona-se com a importância da prática no curso, um aspecto que a maioria acredita pouco atendida, como se depreende da fala:

(...) o curso foi bom, seria melhor se houvesse maior contato com a 
comunidade, com a abertura da brinquedoteca ao público, maior contato com escolas que tenham propostas de sucesso, áreas nas quais o pedagogo atua, enfim, se aprendemos o tempo todo que o importante é sermos os mediadores na construção do conhecimento de nossos futuros alunos, então porque os professores do curso de pedagogia ficam grande parte do tempo expondo sua aula de forma tão tradicional? (ALUNO 3).

Ou ainda outro aluno que, apesar de reconhecer a qualidade dos professores, afirma: "o curso deve ter educadores mais comprometidos e conteúdos mais reais, de acordo com o cotidiano nas escolas. Além disso, deve propor atividades mais práticas, depoimentos e palestras com profissionais da área para que possam trazer suas experiências" (ALUNO $5)$.

Uma questão relevante para a formação do pedagogo diz respeito ao conteúdo específico do ensino fundamental, área na qual atuarão. Entretanto, como abordar essa questão no curso de pedagogia? A dificuldade desse equacionamento pode ser destacada na fala de uma aluna que aponta:

Em relação ao currículo, deve ser mantido, mas a didática dos professores deve ser modificada, pois no terceiro ano, quando tínhamos aulas de matemática, artes, história e geografia, eu imaginava se seriam passados para nós a didática, as maneiras e meios de se atuar nessas áreas dentro da sala de aula. E o que foi passado foi matéria relativa ao ensino fundamental e não como essas matérias deveriam ser passadas! $\mathrm{Na}$ verdade, o que realmente faltou foi a prática e a didática do curso! (ALUNO 40).

Outros abordaram a mudança de professores no meio do curso, o que não consideraram saudável para o bom andamento da disciplina, pois se atribuiu à instituição a responsabilidade das trocas de docentes durante o percurso formativo, como se depreende da fala que segue: "a universidade deveria manter os professores fixos, evitando a saída de profissionais do Ensino Superior, evitando a rotatividade de professores e atraindo mais profissionais de alta qualidade" (ALUNO 9). Houve, ainda, reclamação do acúmulo de atividades, tais como, muitas disciplinas, Trabalho de Conclusão de Curso (TCC) e estágios, um aspecto relevante para o planejamento curricular. Nem sempre as decisões curriculares confirmam-se como as mais adequadas para quem irá cumpri-la. Escolhas curriculares são decisões de caráter político, como apontam os autores Silva (1999), Apple (2006), Santomé e (1989) indicando um conjunto de práticas que produzem significados e identidades. As dificuldades apontadas pelos alunos sugerem que uma revisão curricular 
se faz necessária para esclarecer a formação pretendida.

Nos estudos conduzidos por Fazenda (2011, p. 13) destacam-se alguns cuidados necessários para uma proposta de formação interdisciplinar:

\begin{abstract}
A formação na educação à, pela e para a interdisciplinaridade se impõe e precisa ser concebida sob bases específicas, apoiadas por trabalhos desenvolvidos na área, trabalhos esses referendados em diferentes ciências que pretendem contribuir desde as finalidades particulares da formação profissional até a atuação do professor. A formação à interdisciplinaridade (enquanto enunciadora de princípios) pela interdisciplinaridade (enquanto indicadora de estratégias e procedimentos) e para a interdisciplinaridade (enquanto indicadora de práticas na intervenção educativa) precisa ser realizada de forma concomitante e complementar.
\end{abstract}

Mais um aspecto relevante e nem sempre refletido nas discussões sobre formação de professores diz respeito à coordenação e gestão do curso propriamente dito. Neste caso, os alunos reclamaram quanto à centralização das decisões, com uma gestão autoritária e, aparentemente, com atitudes que negariam a efetivação de uma proposta pedagógica interdisciplinar. Entretanto, mesmo a queixa sendo feita por poucos alunos (no conjunto de 46, apenas 5 apontaram a gestão autoritária), para uma discussão mais apropriada seria necessária uma investigação aprofundada e cuidadosa sobre esse aspecto.

\title{
Ser pedagogo e os dados da pesquisa
}

A questão central do trabalho foi a de investigar o significado de ser pedagogo para os alunos egressos do novo Curso de Pedagogia - Licenciatura e tentar captar se a proclamada formação interdisciplinar estabelecida no projeto pedagógico do curso em estudo foi reconhecida por eles.

Buscou-se, antes, conhecer o significado atribuído ao pedagogo por teóricos que se têm debruçado nesse questionamento. Encontrou-se em Saviani (2008, p. 1) um significado de Pedagogia, quando diz o autor:

(...) entendida como o modo de apreender ou de instituir o processo educativo (...) a Pedagogia desenvolveu-se em íntima relação com a prática educativa, constituindo-se como a teoria ou ciência dessa prática, sendo, em determinados contextos, identificada com o próprio modo intencional de realizar a educação.

Cruz (2011, p. 152), afirma que "ser pedagogo requer fazer pedagogia, ou seja, teorizar sobre a educação, projetar, implementar, acompanhar e avaliar processos educacionais em diferentes contextos". 
Libâneo (2001, p. 6), por sua vez, afirma que:

Há, de fato, uma tradição na história da formação de professores no Brasil segundo a qual pedagogo é alguém que ensina algo. Essa tradição teria se firmado no início da década de 30 , com a influência tácita dos chamados 'pioneiros da educação nova', tomando o entendimento de que o curso de Pedagogia seria um curso de formação de professores para as séries iniciais da escolarização obrigatória.

Nóvoa (2001, p. 2), em estudos anteriores, destaca que o

(...) pedagogo existe na zona de encontro entre a prática e a teoria. A sua palavra não lhe vem apenas da experiência, mas é nela que encontra o seu sentido. O seu pensamento não é uma mera especulação teórica, mas antes um esforço para reflectir sobre a acção educativa.

Complementando, no limite desse texto, pode-se citar que Brzezinski (2011, p. 123), afirma que:

As identidades do pedagogo, (...) vão se delineando em nosso país sob certas determinações das políticas da formação dos profissionais da educação que se materializam em diplomas legais ou instrumentos normativos como, por exemplo, decretos, leis, portarias, resoluções, pareceres, e que se transformam em atividades educativas quotidianas.

Brzezinski (2011, p. 129), ainda complementa que:

O pedagogo, portanto, deverá ser professor e pesquisador, ainda que os documentos legais insistam na formação do professor da educação infantil e dos anos iniciais do ensino fundamental em lócus extramuros da universidade, em que a pesquisa é pouco valorizada e ainda que, anacronicamente, se mantenha a formação dos especialistas em orientação educacional, administração escolar, supervisão escolar e inspeção escolar para a educação básica (art. 64/Lei n.9.396/1996) em nível de graduação.

A partir dessas definições, vê-se que todos os alunos participantes da pesquisa destacaram a relação entre a Pedagogia e a Educação. Para eles há uma ligação entre esses dois pontos, isto é, uma relação indissociável. Porém, quando questionados sobre o pedagogo que está se formando, a ideia sobrepujante é a do professor, restringindo assim o lócus de atuação do pedagogo à docência, aspecto este privilegiado pelas novas Diretrizes Curriculares Nacionais para o curso de Pedagogia de 2006, conforme art. $4^{\mathrm{o}}$ : 
Art. $4^{\circ}-\mathrm{O}$ curso de Licenciatura em Pedagogia destina-se à formação de professores para exercer funções de magistério na Educação Infantil e nos anos iniciais do Ensino Fundamental, nos cursos de Ensino Médio, na modalidade Normal, de Educação Profissional na área de serviços e apoio escolar e em outras áreas nas quais sejam previstos conhecimentos pedagógicos (BRASIL, 2006).

É interessante observar que mesmo com o foco do curso na formação do docente, alguns alunos conseguem reconhecer outras dimensões no campo de atuação do pedagogo, que vão desde a docência até a gestão, passando inclusive pela pedagogia no ramo empresarial e na saúde, áreas estas não muito exploradas no atual curso. Os alunos ressaltam inclusive que sentiram falta dessa abordagem no curso e que gostariam de ter tido um conhecimento mais consistente sobre essa área de atuação não escolar.

Quando se referem à gestão escolar, eles afirmam que o conteúdo não foi aprofundado. A maioria considera que tem apenas uma base e que para uma futura atuação profissional seria necessário um curso de especialização.

Pela posição que os alunos adotaram na discussão sobre o trabalho nas áreas que a Pedagogia contempla, pode-se depreender que não houve equilíbrio entre todas as formações no decorrer do curso. Os alunos ainda se sentem inseguros em relação à gestão e afirmam que a formação do docente teve maior espaço na graduação. Cruz (2011, p. 158) também reforça esse conceito quando lembra que a partir das novas diretrizes "a formação do professor passa a representar o eixo central do curso, enquanto as demais atividades atinentes ao pedagogo são insuficientemente definidas".

É possível verificar isto mais claramente quando eles são questionados se estão preparados para atuar em todas as áreas de formação da Pedagogia. Como a maioria dos alunos já trabalha com Educação Infantil, é maior o índice de pessoas que se consideram capazes de atuar nessa área, seguido pelo Ensino Fundamental. Poucos se consideram aptos para desempenhar uma atividade no campo da gestão escolar, ainda que tenham feito estágio supervisionado nessa área durante a graduação, provocando a dúvida quanto ao fato de ser o pedagogo, a partir das diretrizes, um profissional preparado apenas para a docência, conforme opções nas propostas curriculares.

Porém, sobre motivação, muitos alegaram desmotivação durante o curso, que aumentava à medida que os assuntos tratados desviavam-se do seu foco de interesse, ou seja, de sua área de atuação. Destaque-se, entretanto, que vários alunos apontaram os professores como grandes motivadores quando se sentiam desanimados. $\mathrm{O}$ apoio oferecido pelo professor tem, pois, influência direta no envolvimento dos alunos com a universidade e com as atividades escolares, e a motivação também pode ser influenciada 
pela ação do professor (GUIMARÃES; BORUCHOVITCH, 2004).

Outro aspecto revelado pelos dados sobre os alunos demonstra que a maioria conseguiu encontrar o que considerava mais importante, ou seja, o conhecimento teórico, apontado por eles como um elemento necessário para realizar uma boa prática profissional, com mais preparo para a resolução de problemas da área educacional.

Saviani (2008, p. 153) corrobora essa colocação quando fala da formação do pedagogo e do espaço universitário:

\begin{abstract}
Parece mesmo recomendável que eles (...) vivam intensamente o clima da universidade; mergulhem nos clássicos da Pedagogia e dos fundamentos filosóficos e científicos da educação. Com esse preparo, estarão municiando-se de ferramentas teóricas que lhes permitirão analisar o funcionamento das escolas de educação infantil e de ensino fundamental, para além do senso comum propiciado por sua experiência imediata vivenciada por longos anos no interior da instituição escolar.
\end{abstract}

Reafirma-se, assim como Saviani (2008), a teoria como pilar de sustentação para a prática educativa, conforme descrito no Projeto Pedagógico (2009, p. 34), que propõe formar:

Um profissional com sólida formação teórica, técnica, científica e pedagógica, que compreenda a multidimensionalidade do processo educativo - a dimensão humana, técnica e política - e esteja comprometido com seu contínuo aperfeiçoamento teórico-prático. Em síntese, objetiva formar um profissional capaz de investigar, refletir, gerar conhecimento, gerir e ensinar tanto no âmbito escolar como em espaços não escolares.

Quando conhecem os teóricos, as metodologias, a forma como se dá o ensinoaprendizagem ou mesmo as políticas públicas para educação, o aluno consegue refletir, ordenar, sistematizar e ser crítico, alcançando assim o objetivo da Pedagogia que é oferecer uma visão global de todo o processo educativo, que não se reduz apenas à sala de aula. O estudo teórico é tido como uma condição essencial para pensar, propor, implementar e avaliar o trabalho pedagógico (CRUZ, 2011).

No que tange às expectativas quanto aos objetivos do curso e se foram alcançadas, o ponto crucial é o dilema teoria/prática. Assim, uma das queixas é a quantidade excessiva de teoria em relação à prática, o que parece ser um tanto contraditório, pois, ao mesmo tempo, os alunos valorizaram o embasamento teórico. Provavelmente, a queixa seja sobre 
o equilíbrio entre essa teoria e a prática na sala de aula. Esse é um dilema antigo e Saviani (2008) inclusive afirma que os professores universitários defendem a teoria em cursos de formação, desprezando muitas vezes o apelo dos alunos pela prática.

Após as Diretrizes Curriculares de 2006, houve uma modificação significativa nas orientações a respeito da formação do pedagogo. O espaço que outrora era dedicado às disciplinas de fundamentos foi dividido com as metodologias e didática específicas, conteúdos que estão diretamente ligados à formação do professor, novo perfil proposto pelas diretrizes.

Neste caso, entretanto, os alunos continuam afirmando que o curso é muito teórico, enquanto os especialistas defendem que a teoria foi colocada em segundo plano após as Diretrizes. Claro está que teoria e prática são elementos indissociáveis no processo educativo e que uma dá respaldo para que a outra aconteça, mas, ainda neste caso, não foi encontrado o caminho. Para Saviani (2008, p. 132):

Essa orientação metodológica recupera a unidade da atividade educativa no interior da prática social articulando seus aspectos teóricos e práticos que se sistematizam na Pedagogia concebida ao mesmo tempo como teoria e prática da educação.

Pela fala dos alunos, pode-se inferir que esperavam uma prática que os preparasse para lidar com as dificuldades a serem enfrentadas nas salas de aulas nas quais passariam a atuar e esperavam ainda receber orientação sobre as atitudes pertinentes.

Nem mesmo os estágios previstos de trezentas horas em três frentes - gestão escolar, docência em Educação Infantil e nos anos iniciais do Ensino Fundamental asseguraram aos alunos o contato com aquilo que entendem como prática. O estágio, no Projeto Pedagógico (2009, p. 103), “constitui-se, assim, em espaços problematizadores, instigantes, avaliadores, enfim, ponto central das práticas de formação profissional”, um espaço no qual os alunos possam reflexionar sobre teoria e a prática, ensino-aprendizagem e o papel que o educador ocupa nesse cenário. Leva a crer que o curso, as disciplinas e as experiências adquiridas ao longo da graduação devem convergir para o estágio curricular supervisionado, sendo a hora de se colocar na posição de professor, isto é, o momento de deixar de lado as incertezas e partir para a ação docente (PIMENTA, 2006).

Ao buscar a construção de uma proposta pedagógica comprometida com a interdisciplinaridade, tornou-se necessário o movimento de integração entre as disciplinas e ao mesmo tempo um processo de revisão e atualização de conteúdos e dinâmicas, dentro de cada uma das disciplinas previstas na matriz curricular. O Projeto Pedagógico considera 
que a interdisciplinaridade propõe novas relações entre as disciplinas, ampliando os espaços de intercâmbio dinâmico e experiências pedagógicas inovadoras. A opção pela interdisciplinaridade também tinha o compromisso expresso de propor a reflexão "sobre o tempo necessário para o processo de formação, exigência para o assentamento das novas práticas e modos vivenciados no curso". Além disso, a interdisciplinaridade, nesse caso, era considerada

(...) uma experiência prática e sem dúvida vivenciada coletivamente, [provocando] o diálogo, possibilitando a cada participante $o$ reconhecimento do que lhe falta e do que tem para contribuir, ampliando as trocas com a atitude de humildade requerida para receber dos outros (PROJETO PEDAGÓGICO, 2009, p. 34).

Entretanto, no quesito currículo e interdisciplinaridade, não houve claro reconhecimento da proposição expressa no Projeto Pedagógico. A interdisciplinaridade propõe a interação entre disciplinas aparentemente distintas, que surge para superar a fragmentação e proporciona um diálogo entre as disciplinas. O currículo de curso em análise facilita a interdisciplinaridade ao propor disciplinas que estão ligadas, que se complementam. Os alunos acreditam que houve, sim, essa tentativa, embora nem sempre tenha sido explícita. Alguns citam que os professores propunham atividades que envolviam duas disciplinas ou mais e, nesse momento, essa interdisciplinaridade era por eles claramente percebida. É importante ressaltar que a interdisciplinaridade pode possuir diferentes perspectivas, mas pelo apurado com os alunos foi possível concluir que essa proposta deve ficar mais clara para que possa ser percebida.

Mas, entre os depoimentos, há reconhecimento por parte dos alunos de que "dentro das aulas os professores sempre falaram muito sobre a interdisciplinaridade. Fomos formados acreditando nela. Pudemos ter contato com algumas situações de interdisciplinaridade ao longo do curso que foram muito proveitosas" (ALUNO 33).

Ao investigar como os alunos se posicionam acerca do Projeto Pedagógico estabelecido pelas Novas Diretrizes Curriculares para o Curso de Pedagogia de 2006, o que se percebeu é que a maioria desconhece esse tema e, portanto, não podem expressar opinião sobre o assunto.

Relativamente ao horário do curso e a duração das aulas, o grupo dividiu-se em sua manifestação, pois parte dos alunos considerou estressante manter quatro aulas da mesma disciplina num mesmo dia, extrapolando, muitas vezes, o tempo necessário para tratar de um determinado tema. Tal queixa parece indicar que a docência, na educação superior e mais especificamente em curso de licenciatura ainda merecem atenção. 
$\mathrm{O}$ art. $5^{\circ}$ das Diretrizes Curriculares Nacionais para o Curso de Graduação em Pedagogia - Licenciatura propõe a formação do que se tem identificado como superprofessor, ou seja, um profissional capacitado para atuar em várias frentes e desempenhar múltiplas funções. Nesse caso, os alunos, acreditam ser impossível a formação de um profissional com outras tantas competências, para além da docência e gestão escolar, no atual curso de graduação.

\section{Considerações finais}

O questionário respondido propõe também refletir sobre o que deveria ser mudado e o que deveria ser mantido no currículo, no Projeto Pedagógico e no horário do curso que foi concluído. Essa questão, em particular, permitiu aos alunos apontar o que eles acreditam que tenha funcionado e o que não funcionou no curso. Nesse momento, sinalizaram: a necessidade da prática; o comprometimento dos professores em não saírem durante o período letivo, uma vez que as demissões no percurso provocaram certa instabilidade no curso e aproveitaram para destacar o papel da Universidade em tentar manter os talentos, neste caso, os professores. Apontaram ainda que as questões administrativas do curso deveriam ter sido ajustadas em parceria com os alunos, uma vez que indicaram uma coordenação excessivamente centralizadora, pouco interessada em ouvir e acolher as demandas deles. No que se refere a maiores possibilidades de formação sugeriram o uso mais rotineiro da brinquedoteca; explorar um pouco mais a Pedagogia fora do contexto escolar; novas alternativas na didática das disciplinas para que os alunos encontrem mais significado para o que estão aprendendo; e conteúdos mais próximos da realidade educativa, na qual passarão a atuar.

Quanto ao futuro profissional, eles acreditam que serão bem-sucedidos e que dispõem das capacidades necessárias para o desempenho da docência. De suas respostas, depreende-se que os não atuantes na área da educação, sentem-se, agora, preparados para assumir essa responsabilidade e trabalhar de acordo com a teoria transmitida. Quanto àqueles já atuantes nessa área, e que foram buscar conhecimento teórico para superar métodos tradicionais e embasar sua prática, consideraram-se mais críticos, prontos para desenvolver um trabalho baseado no que aprenderam no curso de Pedagogia.

Quando se confessam com objetivos e metas definidas e conscientes de que escolheram a melhor área profissional para si, resta-se convencer de terem alcançado os objetivos estabelecidos pela Pedagogia, quais sejam, reflexão, ordenação, sistematização e crítica do processo educativo das crianças e adolescentes. Entretanto, apesar de apontarem que nem sempre a interdisciplinaridade como opção de organização curricular e de atitude pedagógica ficou clara para eles, pode-se reconhecer que o processo formativo vivenciado deu aos alunos uma possibilidade motivadora que os impulsionou em busca das relações 
com os conteúdos trabalhados em sala de aula. Concluindo, é possível reconhecer que, apesar das queixas da ausência da prática, sentiram-se provocados a desenhar uma nova "tessitura de um ambiente interativo, entrelaçando os saberes e as pessoas, ampliando o conceito, na prática, da construção coletiva” (PROJETO PEDAGÓGICO, 2009, p. 34).

Para finalizar, convém trazer à luz as reflexões de Fazenda (1991) acerca das possibilidades de construção de uma interdisciplinaridade em ação, quando reafirma categorias fundamentais para o trabalho educativo interdisciplinar, entre as quais se pode destacar o diálogo, o envolvimento e comprometimento complementado por uma atitude de responsabilidade.

\section{Referências}

APPLE, Michael W. Ideologia e currículo. 3. ed. Porto Alegre: Artmed Editora, 2006.

BOGDAN, Roberto C.; BIKLEN, Sari Knopp. Investigação qualitativa em educação. Porto / Portugal: Porto, 1991.

BRASIL. Lei Federal no . 9.394, de 20 de dezembro de 1996. Estabelece as diretrizes e bases da educação nacional. <Disponível em: $<$ http://www.planalto.gov.br/ccivil_03/ leis/19394.htm>. Acesso em: 23 mai. 2012.

Conselho Nacional de Educação. Resolução CNE no ${ }^{0}$, de 15 de maio de 2006. Institui diretrizes curriculares nacionais para o curso de graduação em Pedagogia, licenciatura. Diário Oficial da União, 2006. 16 maio 2006. Seção 1, p.11.

BRZEZINSKI, Iria. Pedagogo: delineando identidade(s). Revista UFG, a. 13, n. 10, Jul. 2011. Disponível em: <http://projetos.extras.ufg.br/joomla_proec/revista_ufg/ Revista\%20UFG\%20Julho\%20-\%202011/arquivos_pdf/iria_brzezinski.pdf >. Acesso em: jul. 2014.

CASTRO, Magali de. A formação de professores e gestores para os anos iniciais da educação básica: das origens às diretrizes curriculares nacionais. RBPAE, v. 23, n. 2, p. 199-227, mai./ago. 2007. Disponível em: <http://seer.ufrgs.br/rbpae/article/ view/19126>. Acesso em: 19 ago. 2014.

CRUZ, Giseli Barreto da. Curso de Pedagogia no Brasil: história e formação com pedagogos primordiais. Rio de Janeiro: WAK, 2011.

FAZENDA, Ivani Catarina Arantes. Interdisciplinaridade: um projeto em parceria. São Paulo: Loyola, 1991. Coleção Educar. v. 13.

Interdisciplinaridade: história, teoria e pesquisa. Campinas: Papirus, 1994.

Interdisciplinaridade: qual o sentido? São Paulo: Paulus, 2003.

Desafios e perspectivas do trabalho interdisciplinar no Ensino Fundamental: contribuições das pesquisas sobre interdisciplinaridade no Brasil: o reconhecimento 
de um percurso. Interdisciplinaridade, São Paulo, v. 1, n. 1, out. 2011. Disponível em: $<$ http://revistas.pucsp.br/index.php/interdisciplinaridade/article/view/16202/12210>. Acesso em: ago 2014.

GUIMARÃES, Sueli Édi Rufini; BORUCHOVITCH, Evely. O estilo motivacional do professor e a motivação intrínseca dos estudantes: uma perspectiva da teoria da autodeterminação. Psicologia: Reflexão e Crítica, Porto Alegre, v. 17, n. 2, p. 143-150, 2004. Disponível em: <http://www.scielo.br/pdf/prc/v17n2/22466.pdf > . Acesso em: 25 mai. 2012.

HAAS, Celia Maria. A interdisciplinaridade na construção de um projeto de universidade: a paixão pela prática. 1996. Tese (Doutorado em Educação). Pontifícia Universidade Católica - PUC-SP, São Paulo, 1996.

Interdisciplinaridade: uma nova atitude docente. Olhar De Professor, Ponta Grossa, v. 10, n. 1, p. 179-193, 2007. Disponível em: <http://www.uepg.br/ olhardeprofessor>. Acesso em: 18 ago. 2014.

LAWN, Martin. Os professores e a fabricação de identidades. Currículo sem Fronteiras, v. 1, n. 2, p. 117-130, jul./dez. 2001.

LENOIR, Y. Três interpretações da perspectiva interdisciplinar em educação em função de três tradições distintas. Revista E-Currículum, São Paulo, v. 1, n. 1, 2005. Disponível em: <http://www.pucsp.br/ecurriculum>. Acesso em: 23 ago. 2014.

LIBÂNEO, José Carlos. Pedagogia e pedagogos: inquietações e buscas. Revista Educar, Curitiba, n. 17, p. 153-176, 2001. Editora da UFPR. Disponível em: <http:// www.educadores.diaadia.pr.gov.br/arquivos/File/2010/artigos_teses/Pedagogia2/ apedagogiaepedagogos.pdf $>$. Acesso em: 21 jan. 2014.

LÜDKE, Menga; ANDRÉ, Marli E.D.A. Pesquisa em educação: abordagens qualitativas. São Paulo: EPU, 1986.

NÓVOA, António. Eu pedagogo me confesso: diálogos com Rui Grácio.

Universidade de Lisboa/Portugal, 2001. Disponível em: <http://repositorio.ul.pt/ bitstream/10451/4821/1/08712212_2001_1_23.pdf>. Acesso em: 21 jan. 2014.

PIMENTA, Selma Garrido. O estágio na formação de professores: unidade teoria e prática? São Paulo: Cortez, 2006.

PROJETO PEDAGÓGICO DO CURSO DE PEDAGOGIA DA UNIVERSIDADE MUNICIPAL. Licenciatura em Pedagogia. São Paulo. 2009. (Mimeografado).

SANTOMÉ, Jurjo Torres. Globalização e interdisciplinaridade: o currículo integrado. Porto Alegre: Artes Médicas,1998.

SAVIANI, Dermeval. A Pedagogia no Brasil: história e teoria. Campinas: Autores Associados, 2008.

SILVA, T. T. Documentos de identidade: uma introdução às teorias do currículo. Belo Horizonte: Autêntica, 1999. 